\title{
Analisis Tingkat Kepuasan Mahasiswa pada Layanan Sistem Informasi Akademik Studi Kasus Universitas X Menggunakan Metode Fuzzy Service Quality
}

\author{
Anwar Sodik*, Muhammad Ma'sum \\ Jurusan Sistem Informasi, Fakultas Teknik Elektro dan Teknologi Informasi, \\ Institut Teknologi Adhi Tama Surabaya, Surabaya, Indonesia \\ Email: *anwar@itats.ac.id
}

\begin{abstract}
In the current digital era, information technology is widely applied in an organization to increase productivity and efficiency. One of them is University $X$ which has an Academic Information system. However, the academic information system currently used has no assessment related to service satisfaction by students as active users. Therefore, an information system is needed to analyze the level of student satisfaction in academic information system services using the Fuzzy Service Quality method. The steps taken by the researcher are distributing questionnaires randomly for students from the 2017 to 2020 class as active users. The results of respondents' answers are processed using the Fuzzy Service Quality (F-SERVQUAL) method based on 5 dimensions, namely reliability, responsiveness, empathy, assurance and tangibles. From the results of the analysis, it was found that the level of satisfaction with the academic information system service of University $X$ was $86 \%$ from 166 data samples.
\end{abstract}

Keywords: Academic Information System, Fuzzy Service Quality, Satisfaction Questionnaire

\begin{abstract}
Abstrak
Pada era digital saat ini, teknologi informasi banyak diterapkan di dalam suatu organisasi guna meningkatkan produktivitas dan efisiensi, salah satunya yakni Universitas X yang memiliki Sistem Informasi Akademik. Namun, pada sistem informasi akademik yang dipergunakan saat ini masih belum terdapat penilaian terkait kepuasan layanan oleh mahasiswa sebagai pengguna aktif. Oleh karena itu, diperlukan sebuah sistem informasi analisis tingkat kepuasan mahasiswa pada layanan sistem informasi akademik dengan menggunakan metode Fuzzy Service Quality. Tahapan yang dilakukan peneliti yaitu membagikan kuesioner secara random untuk mahasiswa angkatan tahun 2017 sampai 2020 sebagai pengguna yang masih aktif. Hasil dari jawaban responden diolah menggunakan metode Fuzzy Service Quality (F-SERVQUAL) berdasarkan lima dimensi, yaitu reliability, responsiveness, empathy, assurance, dan tangible. Dari hasil analisis, diperoleh tingkat kepuasan pada layanan sistem informasi akademik Universitas X sebesar 86\% dari 166 sampel data.
\end{abstract}

Kata kunci: Fuzzy Service Quality, Kuesioner kepuasan, Sistem Informasi Akademik

\section{Pendahuluan}

Universitas X memiliki berbagai macam sistem informasi yang digunakan untuk mendukung berjalannya proses bisnis guna mengelola seluruh kegiatan akademik. Sistem informasi yang digunakan oleh Universitas $\mathrm{X}$ sendiri memiliki beberapa jenis, yaitu sistem informasi akademik, sistem informasi kepegawaian, sistem informasi penjaminan mutu, sistem informasi jual data, dan beberapa sistem informasi pendukung lainnya. Lembaga Pengolah Data Elektronik (LPDE) pada Universitas $\mathrm{X}$ sendiri memiliki peran sebagai tim pengembang dari sistem informasi yang ada guna meningkatkan layanan maupun mutu dari instansi. Pengembangan sistem informasi yang ada pun akan terus berjalan sesuai dengan kebutuhan yang ada. Akan tetapi, saat ini masih belum ada penilaian kepuasan terhadap layanan sistem informasi untuk melakukan validasi bahwa sistem yang telah dikembangkan dapat membantu mahasiswa dalam kegiatan akademik. 
Dalam upaya untuk menentukan penilaian kepuasan layanan sistem informasi akademik dapat menggunakan sebuah metode yaitu Fuzzy Service Quality (F-SERVQUAL). Fuzzy Service Quality merupakan sebuah metode pengembangan dari metode penilaian service quality dengan pendekatan fuzzy dalam mengukur kepuasan dari pengguna sehingga dapat memberikan informasi kepuasan lebih detail dan akurat. Nantinya, hasil dari penelitian ini dapat digunakan sebagai produk aplikasi untuk menganalisis tingkat kepuasan mahasiswa pada teknologi informasi yang ada pada Universitas X.

\section{Metode}

Sampel penelitian menggunakan metode random sampling, random sampling merupakan suatu teknik sampling yang dipilih secara acak. Berdasarkan rumus tersebut, sampel yang diambil dalam penelitian ini minimal berjumlah 98 responden, yang berasal dari 5219 orang mahasiswa aktif di Universtias X, dengan tingkat ambang batas kesalahan yaitu 10\% [1] serta menggunakan instrumen kuesioner yang telah ditentukan.

$n=\frac{5219}{(1+(5219 \times 0.1))} \rightarrow n=\frac{5219}{(1+(52.19)} \rightarrow n=98$

Penelitian ini adalah penelitian kuantitatif, karena penelitian ini merupakan penelitian yang didasarkan pada data angka serta menganalisa menggunakan metode Fuzzy Service Quality [2] . Data yang digunakan pada penelitian ini adalah data primary atau utama yang didapatkan dengan melakukan survei menggunakan kuesioner kepada mahasiswa Universitas X. Responden diharuskan untuk mengisi semua kuesioner secara utuh, karena hasil dari kuesioner akan digunakan sebagai data primer. Gambaran dari penelitian ini ditunjukkan pada Gambar 1.

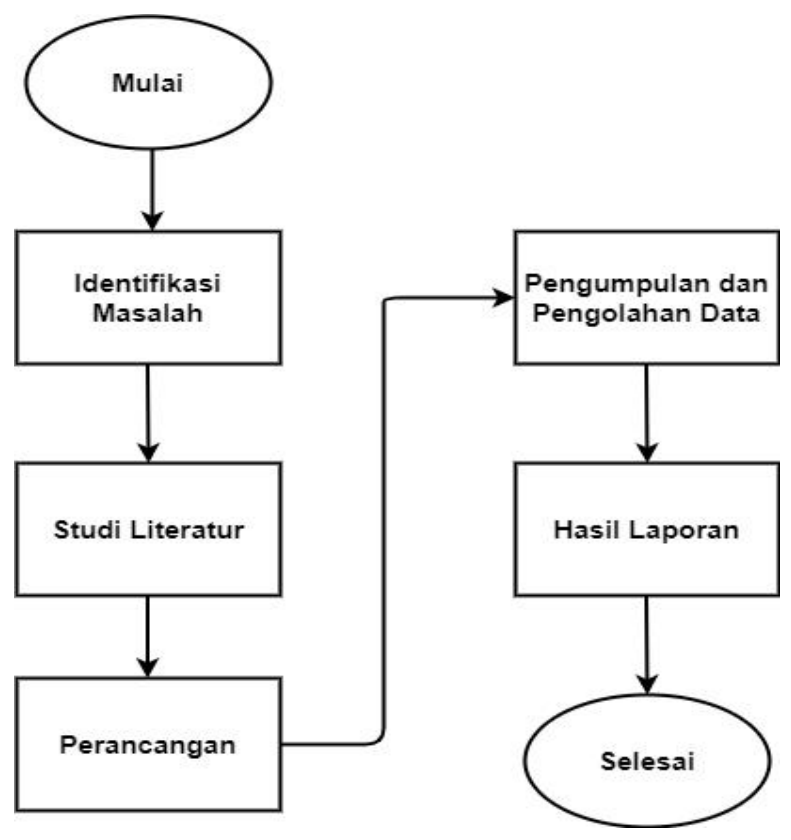

Gambar 1. Alur Penelitian

Metode fuzzy digunakan untuk mendukung proses olah data pada sistem yang dikembangkan pada penelitian yang dilakukan. Tahap pertama yaitu penentuan fuzzy set, dalam tahapan ini dilakukan pengkonversian nilai bobot kedalam fuzzy number, nilai pembobotan yang digunakan antara nilai 1 sampai dengan 5, setiap nilai bobot akan dikonversi kedalam fuzzy number dengan pola $(\mathrm{a}, \mathrm{b}, \mathrm{c})$. Maksud dari pola tersebut adalah a merupakan nilai terendah dari nilai bobot, $b$ merupakan nilai bobot 
asli dan c merupakan nilai bobot tertinggi. Dari fuzzy number yang telah dikonversi, maka diperoleh fuzzy set yang digunakan pada tahap fuzzyfikasi [3].

Tahap selanjutnya yaitu fuzzyfikasi, fuzzyfikasi yaitu aktivitas untuk mendapatkan nilai komposisi dari fuzzy number seluruh responden dengan menggunakan rumus Fuzzyfikasi [4]. Tahap terakhir yaitu defuzzyfikasi, pada tahap ini digunakan untuk mencari nilai tunggal dari bobot rata-rata dari masing masing atribut yang telah dihitung menggunakan rumus Defuzzyfikasi. Adapun pengujian yang dilakukan disini yaitu melalui instrumen kuesioner. Oleh karena itu, penulis merancang instrumen kuesioner untuk menghasilkan sebuah instrumen.

\section{Hasil dan Pembahasan}

Adapun pengujian yang dilakukan disini yaitu melalui instrumen kuesioner. Oleh karena itu, penulis merancang instrumen kuesioner untuk menghasilkan sebuah instrumen seperti ditunjukkan pada Tabel 1.

Tabel 1. Instrumen Kuesioner

\begin{tabular}{cll}
\hline Dimensi & Kode & \multicolumn{1}{c}{ Kuesioner } \\
\hline Tangibles (Bukti & Q1 & Tampilan interface SIAKAD \\
Terukur) & Q2 & SIAKAD Mudah Dioperasikan \\
& Q3 & Fitur Fitur yang ada pada SIAKAD \\
& Q4 & Kemampuan Siakad dalam memberikan pelayanan kepada mhs \\
& Q5 & SIAKAD dapat diakses kapan saja \\
& Q6 & SIAKAD yang diterapkan sudah menyesuaikan dengan perkembangan teknologi \\
\hline Reability & Q7 & Mudah melakukan edit data Mahasiswa pada SIAKAD \\
(Kehandalan) & Q8 & Ketepatan informasi jadwal kuliah yang ada pada SIAKAD \\
& Q9 & Ketepatan Informasi dosen yang diberikan kepada mahasiswa melalui SIAKAD \\
& Q10 & Pengisian KRS melalui SIAKAD \\
& Q11 & Informasi Nilai mahasiswa melalui SIAKAD \\
& Q12 & Ketepatan Informasi Pembayaran (SPP, Daftar Nilai, Skripsi, Yudisium dll) melalui \\
\hline Responsiveness & Q13 & SIAKAD \\
(Daya Tanggap) & Q14 & Dosen pengajar matakuliah sesuai dengan SIAKAD \\
& Q15 & SIAKAD cepat tanggap apabila terjadi perubahan kurikulum \\
& Q16 & Cetak KRS pada SIAKAD cepat dan mudah \\
& Q17 & Nilai yang ada pada SIAKAD sudah sesuai dengan nilai yang dosen berikan \\
\hline Assurance & Q18 & Keamanan data mahasiswa pada SIAKAD \\
(Jaminan) & Q19 & Keakuratan Informasi pengumuman yang ada pada SIAKAD \\
& Q20 & Keamanan melakukan tagihan pembayaran melalui SIAKAD \\
& Q21 & Pemberitahuan informasi pengganti dosen mata kuliah \\
& Q22 & Keakuratan pengisian KRS pada SIAKAD \\
Emphaty & Q23 & Informasi nilai yang ada pada SIAKAD selalu terupdate \\
\hline & Q24 & Memberikan kemudahan kepada mahasiswa untuk melakukan perubahan data mahasiswa \\
& Q25 & mempermudah mahasiswa untuk mencari jadwal kuliah \\
& Q27 & mempermudah mahasiswa dalam mencari kontrak perkuliahan \\
& mempermudah mahasiswa untuk mencari jadwal ujian \\
\hline & SIAKAD sangat membantu dalam urusan akademik \\
\hline
\end{tabular}

Pengujian validitas dan reliabilitas kuesioner dilakukan untuk mengukur kemampuan instrumen untuk mengukur objek yang diukur. Pada pengujian kali ini peneliti menggunakan metode pearson dan uji reabilitas menggunakan metode Spearman [5]. Dari hasil yang telah dilakukan menunjukkan instrumen kuesioner telah valid dan hasil dari uji reliabel.

$r x y=\frac{N \sum x y-\left(\sum x\right)\left(\sum y\right)}{\sqrt{\left[N \sum x^{2}-\left(\sum x\right)^{2}\right]} \sqrt{\left[N \sum y^{2}-\left(\sum y\right)^{2}\right]}}$ 


$$
\begin{aligned}
& r x y=\frac{(166)(80681)-(667)(19728)}{\sqrt{(166)(2785)-(667)^{2}} \sqrt{\left[(166)(2385716)-(19728)^{2}\right.}} \\
& r x y=0,679
\end{aligned}
$$

Selanjutnya peneliti melakukan analisis gap, hal tersebut dilakukan untuk memperoleh nilai dari harapan dan persepsi. Nilai harapan dan persepsi didapatkan dari implementasi metode Fuzzy Service Quality. Dari hasil fuzzyfikasi berdasarkan pengkonversian fuzzy number yang telah disebutkan pada Tabel 1, maka diperoleh hasil metode arithmetic mean seperti ditunjukkan Tabel 2.

\begin{tabular}{|c|c|c|c|c|c|c|}
\hline \multirow[t]{2}{*}{ Kode } & \multicolumn{3}{|c|}{ H } & \multicolumn{3}{|c|}{$\mathbf{P}$} \\
\hline & $\boldsymbol{a H}$ & bH & $\boldsymbol{C H}$ & $\boldsymbol{a P}$ & $\boldsymbol{b P}$ & $\boldsymbol{C P}$ \\
\hline Q1 & 3,02 & 4,02 & 4,72 & 3,35 & 4,35 & 4,82 \\
\hline Q2 & 3,21 & 4,21 & 4,80 & 3,46 & 4,46 & 4,87 \\
\hline Q3 & 3,27 & 4,25 & 4,82 & 3,51 & 4,51 & 4,86 \\
\hline Q4 & 3,19 & 4,19 & 4,80 & 3,45 & 4,45 & 4,86 \\
\hline Q5 & 3,36 & 4,36 & 4,83 & 3,66 & 4,66 & 4,89 \\
\hline Q6 & 3,22 & 4,22 & 4,82 & 3,42 & 4,42 & 4,83 \\
\hline Q7 & 3,10 & 4,10 & 4,77 & 3,43 & 4,43 & 4,83 \\
\hline Q8 & 3,33 & 4,33 & 4,84 & 3,61 & 4,61 & 4,90 \\
\hline Q9 & 3,11 & 4,11 & 4,74 & 3,45 & 4,45 & 4,84 \\
\hline Q10 & 3,27 & 4,26 & 4,79 & 3,58 & 4,58 & 4,89 \\
\hline Q11 & 3,36 & 4,36 & 4,86 & 3,57 & 4,57 & 4,87 \\
\hline Q12 & 3,33 & 3,32 & 4,80 & 3,55 & 4,55 & 4,87 \\
\hline Q13 & 3,41 & 4,41 & 4,86 & 3,56 & 4,56 & 4,89 \\
\hline Q14 & 3,27 & 4,27 & 4,81 & 3,54 & 4,54 & 4,89 \\
\hline Q15 & 3,13 & 4,12 & 4,76 & 3,37 & 4,37 & 4,91 \\
\hline Q16 & 3,37 & 4,37 & 4,84 & 3,60 & 4,60 & 4,91 \\
\hline Q17 & 3,21 & 4,21 & 4,80 & 3,53 & 4,53 & 4,89 \\
\hline Q18 & 3,24 & 4,24 & 4,77 & 3,61 & 4,61 & 4,88 \\
\hline Q19 & 3,30 & 4,30 & 4,83 & 3,58 & 4,57 & 4,87 \\
\hline Q20 & 3,29 & 4,28 & 4,80 & 2,54 & 4,54 & 4,86 \\
\hline Q21 & 3,01 & 4,01 & 4,68 & 3,39 & 4,39 & 4,81 \\
\hline Q22 & 3,24 & 4,23 & 4,77 & 3,53 & 4,53 & 4,87 \\
\hline Q23 & 3,17 & 4,17 & 4,76 & 3,47 & 4,47 & 4,83 \\
\hline Q24 & 3,27 & 4,27 & 4,85 & 3,51 & 4,51 & 4,86 \\
\hline Q25 & 3,32 & 4,32 & 4,81 & 3,54 & 4,54 & 4,87 \\
\hline Q26 & 3,21 & 4,20 & 4,78 & 3,49 & 4,49 & 4,87 \\
\hline Q27 & 3,41 & 4,41 & 4,86 & 3,53 & 4,52 & 4,86 \\
\hline Q28 & 3,32 & 4,32 & 4,83 & 3,57 & 4,57 & 4,89 \\
\hline
\end{tabular}

Tabel 2. Hasil Fuzzyfikasi

Pada Tabel 2, H sebagai harapan, $\mathrm{P}$ sebagai persepsi, aH, bH, cH merupakan fuzzy number nilai bawah, tengah, dan atas harapan, dan aP, bP, cP merupakan fuzzy number nilai bawah, atas tengah dan atas persepsi. Setelah melalui proses fuzzyfikasi selanjutnya dilakukan proses deffuzyfikasi, sehingga dari hasil defuzzyfikasi dapat memperoleh nilai gap untuk masing masing aspek kuesioner.

Dari hasil pengolahan metode Fuzzy Service Quality, penilaian berdasarkan data hasil kuesioner menghasilkan nilai akhir dari harapan dan persepsi untuk setiap aspek kuesioner. Pada data yang ada ditunjukkan bahwasanya keseluruhan hasil gap memperoleh nilai positif, yang memiliki arti bahwa aspek layanan yang dinilai telah memberikan kepuasan terhadap responden. Aspek layanan dengan nilai tertinggi adalah aspek dengan kode kuesioner Q21 dengan nilai gap 0,30 sedangkan 
layanan dengan gab terendah yaitu aspek dengan kode kuesioner Q27 dengan nilai gap 0,08, hasil defuzzyfikasi dapat dilihat pada Tabel 3 .

\begin{tabular}{cccc}
\multicolumn{5}{c}{ Tabel 3. Defuzzyfikasi dan Nilai Gap } \\
\hline Kode & H & P & Gap \\
\hline Q1 & 3,92 & 4,17 & 0,25 \\
Q2 & 4,07 & 4,27 & 0,19 \\
Q3 & 4,11 & 4,29 & 0,18 \\
Q4 & 4,06 & 4,25 & 0,19 \\
Q5 & 4,18 & 4,40 & 0,22 \\
Q6 & 4,08 & 4,22 & 0,14 \\
Q7 & 3,99 & 4,23 & 0,24 \\
Q8 & 4,16 & 4,38 & 0,21 \\
Q9 & 3,99 & 4,24 & 0,26 \\
Q10 & 4,10 & 4,35 & 0,24 \\
Q11 & 4,19 & 4,34 & 0,15 \\
Q12 & 4,15 & 4,33 & 0,18 \\
Q13 & 4,23 & 4,34 & 0,11 \\
Q14 & 4,12 & 4,33 & 0,21 \\
Q15 & 4,00 & 4,19 & 0,19 \\
Q16 & 4,19 & 4,37 & 0,18 \\
Q17 & 4,07 & 4,32 & 0,24 \\
Q18 & 4,08 & 4,37 & 0,29 \\
Q19 & 4,14 & 4,34 & 0,20 \\
Q20 & 4,12 & 4,31 & 0,19 \\
Q21 & 3,90 & 4,20 & 0,30 \\
Q22 & 4,09 & 4,31 & 0,23 \\
Q23 & 4,03 & 4,26 & 0,22 \\
Q24 & 4,13 & 4,30 & 0,17 \\
Q25 & 4,15 & 4,31 & 0,16 \\
Q26 & 4,07 & 4,29 & 0,22 \\
Q27 & 4,22 & 4,30 & 0,08 \\
Q28 & 4,16 & 4,34 & 0,19 \\
\hline & & &
\end{tabular}

Dari Tabel 3, dapat dilanjutkan dengan melakukan perhitungan index kepuasan mahasiswa [6].

$I K M=\frac{\sum \mathrm{HP}}{5 \times \sum \mathrm{H}} \times 100 \%$

Dari hasil pengolahan tersebut, didapatkan tingkat kepuasan mahasiswa terhadap layanan sistem informasi akademik yaitu 86\% dari 166 responden.

\section{Kesimpulan}

Hasil jawaban responden (mahasiswa) menunjukkan bahwa tingkat kepuasan akan layanan sistem informasi akademik Universitas X memperoleh persentase hasil sebesar 86\% dari 166 sampel data. Harapannya, hasil penelitian ini dapat menjadi acuan bagi Universitas $\mathrm{X}$ untuk selalu meningkatkan kualitas layanan guna meningkatkan kepuasan mahasiswa. 


\section{Referensi}

[1] N. H. Sudibyo, M. S. Hasibuan, I. Darmajaya, J. Za, P. Alam, and A. Bandar, "The influence of service quality on students satisfactions at private Universities in Bandar Lampung," Int. Conf. Inf. Technol. Bus., no. 9, pp. 291-295, 2015.

[2] H. Sholikah and S. W. Iriananda, "Analisis Kepuasan Pelanggan Travel Menggunakan Metode Fuzzy Service Quality," JOINTECS (Journal Inf. Technol. Comput. Sci., vol. 2, no. 2, pp. 53-58, 2017, doi: 10.31328/jointecs.v2i2.468.

[3] W. O. Widyarto, N. Djamal, and F. Adhim, "Analisis Kualitas Pelayanan Publik dengan Metode Fuzzy-Service Quality (F-Servqual) dan Index Potential Gain Customer Value (IPGCV)," J. Sist. dan Manaj. Ind., vol. 2, no. 2, p. 101, 2018, doi: 10.30656/jsmi.v2i2.769.

[4] S. Thaker and V. Nagori, "Analysis of Fuzzification Process in Fuzzy Expert System," Procedia Comput. Sci., vol. 132, pp. 1308-1316, 2018, doi: 10.1016/j.procs.2018.05.047.

[5] M. Bekerja, T. Kinerja, P. Dengan, M. Metode, and P. Correlation, "Susi Susilawati Harahap," vol. 06, pp. 12-25, 2019.

[6] N. F. Kartika, "Implementasi Fuzzy - Service Quality Terhadap Tingkat Kepuasan Layanan Mahasiswa Implementation of Fuzzy - Service Quality for Student Service Level of Satisfaction,” J. Ilm. SISFOTENIKA, vol. 7, no. 1, pp. 38-49, 2017. 